\title{
Plasmodium Parasitaemia among Pregnant Women in the Niger Delta Region of Nigeria
}

\author{
Ibinabo Laura Oboro', ${ }^{1}$ Omosivie Maduka2* ${ }^{*}$, Terhemen Kasso ${ }^{3}$, Abimbola Temitayo Awopeju${ }^{1}$, \\ Nsirimobu Paul4, Lucy Yaguo-Ide4, Ifeyinwa Nwogo Chijioke-Nwauche5, Mark Ogoro6, \\ Iyeopu Siminialayi ${ }^{7,8}$, Claribel Ifesimama Abam ${ }^{8}$, Alice Romakek Nte ${ }^{4,8}$, \\ Florence Onyemachi Nduka ${ }^{8,9}$, Orikomaba Obunge ${ }^{1,8}$, Chijioke Adonye Nwauche ${ }^{8,10}$ \\ ${ }^{1}$ Department of Medical Microbiology, University of Port Harcourt, Port Harcourt, Nigeria \\ ${ }^{2}$ Department of Preventive and Social Medicine, University of Port Harcourt, Port Harcourt, Nigeria \\ ${ }^{3}$ Department of Obstetrics and Gynaecology, University of Port Harcourt, Port Harcourt, Nigeria \\ ${ }^{4}$ Department of Paediatrics and Child Health, University of Port Harcourt, Port Harcourt, Nigeria \\ ${ }^{5}$ Department of Clinical Pharmacy and Management, University of Port Harcourt, Port Harcourt, Nigeria \\ ${ }^{6}$ Department of Geography and Environmental Management, University of Port Harcourt, Port Harcourt, Nigeria \\ ${ }^{7}$ Department of Pharmacology and Centre for Malaria Research and Phytomedicine, University of Port Harcourt, Port Harcourt, \\ Nigeria \\ ${ }^{8}$ NDDC Professorial Chair on Malaria Elimination and Phytomedicine Research, Centre for Malaria Research and Phytomedicine, \\ University of Port Harcourt, Port Harcourt, Nigeria \\ ${ }^{9}$ Department of Animal and Environmental Biology, University of Port Harcourt, Port Harcourt, Nigeria \\ ${ }^{10}$ Department of Haematology, Blood Transfusion and Immunology and Centre for Malaria Research and Phytomedicine, \\ University of Port Harcourt, Port Harcourt, Nigeria \\ Email: *omosivie.maduka@uniport.edu.ng
}

How to cite this paper: Oboro, I.L., Maduka, O., Kasso, T., Awopeju, A.T., Paul, N., Yaguo-Ide, L., Chijioke-Nwauche, I.N., Ogoro, M., Siminialayi, I., Abam, C.I., Nte, A.R., Nduka, F.O., Obunge, O. and Nwauche, C.A. (2021) Plasmodium Parasitaemia among Pregnant Women in the Niger Delta Region of Nigeria. Advances in Infectious Diseases, 11, 84-94.

https://doi.org/10.4236/aid.2021.111010

Received: January 26, 2021

Accepted: March 20, 2021

Published: March 23, 2021

\begin{abstract}
Introduction: Malaria is a febrile illness caused by the Plasmodium species. The mangrove swamp forest vegetation and high annual rainfall characteristic of the Niger Delta region of Nigeria encourage all year round transmission of malaria. This study aimed to determine the prevalence and speciation of Plasmodium parasitaemia among pregnant women in the Niger Delta region of Nigeria. Methodology: Cross-sectional study carried out in three states of the Niger Delta region; Akwa-Ibom, Delta and Rivers between April and June 2019. Study Sites were chosen by stratified random sampling. Demographic information was collected using pretested interviewer-administered questionnaires via the Open Data Kit application on android mobile phones. Diagnosis was by rapid diagnostic test (RDT) and Microscopy. Ethical approval and informed consent were obtained. Data was analyzed using the SPSS v25 software. Chi-square statistic and Fischer's exact test were used to compare data, all at a 95\% confidence interval and significance level of 0.05 . Results: Two thousand, eight hundred and twenty (2820) pregnant women were studied; 948,
\end{abstract}


Copyright $\odot 2021$ by author(s) and Scientific Research Publishing Inc. This work is licensed under the Creative Commons Attribution International License (CC BY 4.0).

http://creativecommons.org/licenses/by/4.0/ (c) (i) Open Access
992 and 880 from Akwa-Ibom, Delta and Rivers respectively. Overall prevalence of parasitaemia using RDT and Microscopy was $6.8 \%$ and $6.7 \%$ respectively. All except $1 \%$ of malaria was attributed to falciparum species. The other species were plasmodium ovale and plasmodium malariae. Conclusion: The prevalence of Plasmodium parasitaemia among pregnant women in the Niger Delta region of Nigeria has reduced considerably, giving credence to the malaria preventive strategies applied in antenatal care. When properly stored and used as recommended, malaria RDTs compare favorably with microscopy; therefore, no case of malaria should be missed due to a facility's incapability to carry out microscopic diagnosis.

\section{Keywords}

Malaria Parasitaemia, Pregnant Women, Malaria RDT, Microscopy

\section{Background}

Malaria is a febrile illness caused by the protozoan parasites of the genus Plasmodium which until recently was classified into five species: $P$. falciparum, $P$. ovale, P. malariae, $P$. vivax and knowlesi; however, current studies [1] have shown that there are two non-recombining species of ovale (ovale curtisi and ovale wallikeri) which are non-sympatric in nature [2]. Of all these, Plasmodium falciparum is the most common species in virtually all parts of Africa, accounting for up to $98 \%$ of confirmed cases in Nigeria. It is the agent of the most malignant form of malaria, usually presenting with greater morbidity and mortality, mostly among children and pregnant women [3]. P. malariae tends to occur as a mixed infection with $P$. falciparum [4].

Malaria is essentially a disease of the tropics and subtropics particularly the sub-Saharan African region although it has been reported in temperate areas due to migration from the tropics. It is holo-endemic in Nigeria where there is a year-round transmission. Malaria transmission is the highest in Nigeria during the rainy season which usually spans April to September, with the peak of rains between May and July. Rainfall pattern in Nigeria varies largely, with the South having more rains than the North. Annual rainfall decreases northward; rainfall ranges from about 2000 millimeters in the coastal zone (averaging more than 3550 millimeters in the Niger Delta) to 500 - 750 millimeters in the north. The far south is defined by its tropical rainforest climate, where annual rainfall is 1524 to $2032 \mathrm{~mm}$ (60 to 80 inches) per year. The Niger Delta is located on the Atlantic coast of Southern Nigeria encompassing an area of $20,000 \mathrm{~km}^{2}$ and is the world's third largest wetland. The mangrove swamp forest vegetation here encourages all year-round transmission of malaria. Malaria prevalence in Nigeria thus varies widely, ranging from $14 \%$ in the South East Zone to 37\% in the North West Zone [5].

Malaria remains a major public health challenge for developing countries. $\mathrm{Ni}$ geria bears the major portion of this burden as she accounts for $25 \%$ of the glob- 
al malaria burden. Approximately 173 million (97\%) of Nigeria's population is at risk of malaria [6] with greater than half a million new cases recorded in 2017 [7]. Nigeria was one of three (3) countries which had the highest estimated increases in malaria burden in 2017 compared with 2016 [7]. This is worrisome as the Nigeria Malaria Indicator Survey of 2015, had reported a decline in malaria prevalence from $42 \%$ in 2010 to $27 \%$ in 2015 [8].

The bulk (94\%) of all malaria deaths in 2018 occurred in the WHO African Region with pregnant women and children bearing the greatest impact. Children aged under 5 years are the most vulnerable group and accounted for $67 \%$ $(272,000)$ of all malaria deaths globally. The West African sub-region where Nigeria is located was one of two sub-regions in Africa with the highest prevalence (35\%) of exposure to malaria infection in pregnancy. Pregnant women in this region had the highest prevalence of low-birth-weight children $(872,000,16 \%)$ due to malaria in pregnancy [7].

Among the many possible complications of malaria in pregnancy, the most critical are maternal anaemia and delivery of low-birth-weight babies with the associated complications [3]. Beyond financial implications, the indirect costs of malaria cannot be quantified including the long-term effect on cognitive function and educational attainment in children [9] [10]. This situation is worsened by the scourge of multi-drug resistance resulting from improper diagnosis, self-medication, and improper treatment, including use of sub-optimal and incomplete doses of antimalarials.

Light microscopic examination of Giemsa-stained blood films has been recommended by WHO for use in diagnosis of malaria where adequate support for its use is available. Light microscopy however is quite limited in Nigeria especially in rural, hard to reach or poorer settings, as well as where trained personnel are not available. Rapid diagnostic tests on the other hand, are lateral flow devices designed based on antigen-antibody interactions for the qualitative diagnosis of malaria parasite antigens in blood. The target antigens for which RDTs have been designed include the histidine rich protein 2 (HRP2) expressed by Plasmodium falciparum and/or Plasmodium lactate dehydrogenase (pLDH) expressed by all human Plasmodium species [11].

This study aimed to determine the prevalence of Plasmodium parasitaemia among pregnant women in three states of the Niger Delta region of Nigeria, the distribution of the Plasmodium species causing infection and determine the diagnostic efficacy of RDT compared with microscopy.

\section{Materials and Methods}

This was a cross-sectional study carried out among pregnant women in three states of the Niger Delta region of Nigeria, Akwa-Ibom, Delta, and Rivers states between April and June 2019. Eligible participants were those who were attending antenatal care at public or private health facilities in the state.

A sample size of 758 per state was calculated using the sample size formula for single proportion with $27 \%$ prevalence rate of malaria from the 2015 Nigeria 
Malaria indicator survey [8], a degree of accuracy of $0.05 \%$ and $95 \%$ confidence interval, $20 \%$ non-response rate and a multiplication factor of two (2) to compensate for design effect. Stratified sampling was employed to select two local government areas (LGA) each from the three senatorial zones, making a total of six local governments. Computer generated table of random numbers was used to select two heath facilities from two zones and four from the largest zone to get eight health facilities. The sample size was then distributed across these facilities in a proportionate manner based on average antenatal clinic attendance. Systematic sampling was used to select pregnant women from each of the selected health facilities based on sampling interval calculated by dividing the average antenatal attendance by the allocated sample size per facility. Data collection spanned two weeks. Research assistants, data collectors and microscopists were trained on the study protocol for standardization of data collection and laboratory processes. Information was collected using pretested interviewer administered questionnaires using a mobile data collection tool, the Open Data Kit (ODK) on android devices

One millilitre of venous blood was collected from each woman. A rapid diagnostic test was immediately performed using the SD Bioline Malaria Ag P.f Kit (Standard Diagnostics Inc., USA) according to manufacturers' instruction and thereafter, two thin and thick blood smears were made on two clean glass slides per woman. Smears were stained using freshly prepared 3\% Giemsa stain and examined for the Plasmodium species, stage, and density according to World Health Organization's recommendations. Each one of a participant's blood films was read by two independent microscopists. Each microscopist attached to a specimen was blind to the result of the other microscopist. A patient was reported as positive if either one or both tests were interpreted as positive. All patients with infection were managed according to standard of care. Ethical approval was obtained from the ethical boards of the states and facilities and informed consent was obtained from participants before each interview.

Data was presented using summary statistics (frequency and percentages) and analyzed using the SPSS version 25 software. The Chi-square statistic and Fischer's exact test were used for inferential analysis. Decisional analysis using a two-by-two table was done with sensitivity, specificity, positive and negative predictive values, and test accuracy, using microscopy as the gold standard. All analyses were done at a 95\% confidence interval and a significance level of 0.05 .

\section{Results}

A total of two thousand, eight hundred and twenty (2820) pregnant women were studied; nine hundred and forty-eight (948) from Akwa-Ibom state, nine hundred and ninety-two (992) from Delta state and eight hundred and eighty (880) from Rivers state.

\subsection{Sociodemographics}

Study participant's sociodemographic information is shown on Table 1. Across 
Table 1. Socio-demographic characteristics of study participants.

\begin{tabular}{|c|c|c|c|c|}
\hline & $\begin{array}{l}\text { Akwa Ibom } \\
(\mathrm{n}=948), \%\end{array}$ & $\begin{array}{c}\text { Delta } \\
(\mathrm{n}=992), \%\end{array}$ & $\begin{array}{c}\text { Rivers } \\
(\mathrm{n}=\mathbf{8 8 0}), \%\end{array}$ & $\begin{array}{c}\text { Total } \\
(\mathrm{n}=\mathbf{2 8 2 0}) \%\end{array}$ \\
\hline \multicolumn{5}{|l|}{ Age groups } \\
\hline $19-29$ years & $551(58.12)$ & $486(48.99)$ & $372(42.27)$ & $1409(50.0)$ \\
\hline $30-39$ years & $384(40.51)$ & $472(47.58)$ & $483(54.89)$ & $1339(47.4)$ \\
\hline $40-49$ years & $13(1.37)$ & $34(3.43)$ & $25(2.84)$ & $72(2.6)$ \\
\hline \multicolumn{5}{|l|}{ Marital status } \\
\hline Married & $891(93.99)$ & $954(96.17)$ & $860(97.73)$ & 2705 (95.9) \\
\hline Divorced & $1(0.11)$ & $2(0.20)$ & $1(0.11)$ & $4(0.14)$ \\
\hline Single & $54(5.70)$ & $35(3.53)$ & $17(1.93)$ & $106(3.8)$ \\
\hline Widowed & $2(0.21)$ & $1(0.10)$ & $2(0.23)$ & $5(0.18)$ \\
\hline \multicolumn{5}{|l|}{ Education } \\
\hline No formal education & $3(0.32)$ & $4(0.40)$ & $0(0.0)$ & $7(0.25)$ \\
\hline Primary & $42(4.43)$ & $43(4.33)$ & $3(0.34)$ & $88(3.1)$ \\
\hline Secondary & $459(48.42)$ & $484(48.79)$ & $293(33.30)$ & $1236(43.8)$ \\
\hline Tertiary & $444(46.84)$ & $461(46.47)$ & $584(66.36)$ & $1489(52.8)$ \\
\hline \multicolumn{5}{|l|}{ Occupation } \\
\hline Civil servant & $80(8.44)$ & $40(4.03)$ & $80(9.09)$ & $200(7.1)$ \\
\hline Farmer & $12(1.27)$ & $9(0.91)$ & $8(0.91)$ & $29(1.0)$ \\
\hline Public servant & $71(7.49)$ & $49(4.94)$ & $72(8.18)$ & $192(6.8)$ \\
\hline Self-employed & $228(24.05)$ & $185(18.65)$ & $159(18.07)$ & $572(20.3)$ \\
\hline Teacher & $111(11.71)$ & $109(10.99)$ & $117(13.30)$ & $337(12.0)$ \\
\hline Trader & $321(33.86)$ & $432(43.55)$ & $252(28.64)$ & $1005(35.6)$ \\
\hline Others & $125(13.19)$ & $168(16.94)$ & $192(21.82)$ & $485(17.2)$ \\
\hline
\end{tabular}

the three states, half of the study population was aged $19-29$ years (1409; 50.0\%), had tertiary education 1489 (52.8) and were either traders 1005 (35.6) or self-employed 572 (20.3).

\subsection{Prevalence of Plasmodium Parasitaemia}

The detection rate of Plasmodium parasitaemia by RDT and Microscopy is shown in Figure 1.

A total of 191 persons (6.8\%) tested positive for malaria using RDT compared with 188 (6.7\%) who tested positive using microscopy Figure 1.

The highest prevalence of malaria using RDT was found in Akwa-Ibom (8.3\%) state while the lowest prevalence was from Delta state (5.6\%). Microscopy revealed the highest prevalence of malaria from Rivers State (8.4\%) while Akwa-Ibom had the lowest prevalence (3.5\%).

\subsection{Distribution of Malaria Parasite Species}

Figure 2 shows that majority (99\%) of infected women had $P$. falciparum 


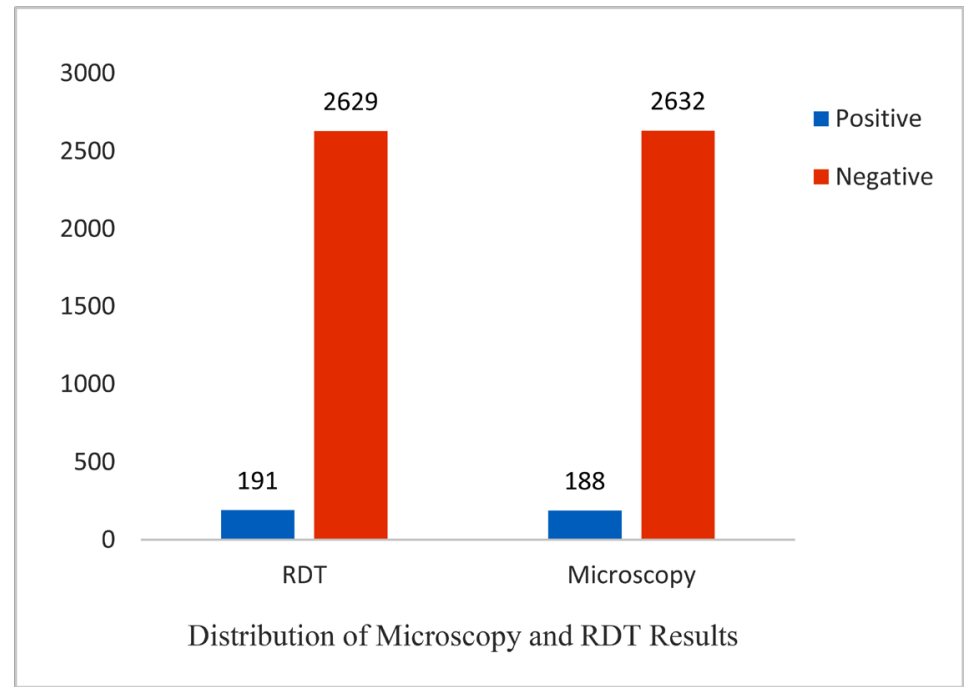

Figure 1. Distribution of microscopy and RDT results.

Table 2. State-based distribution of diagnostic outcome.

\begin{tabular}{lccccc}
\hline \multicolumn{2}{c}{ Results } & $\begin{array}{c}\text { Akwa Ibom } \\
\mathbf{n = 9 4 8 , ( \% )}\end{array}$ & $\begin{array}{c}\text { Delta } \\
\mathbf{n}=\mathbf{9 9 2 , ( \% )}\end{array}$ & $\begin{array}{c}\text { Rivers } \\
\mathbf{n}=\mathbf{8 8 0 , ( \% )}\end{array}$ & $\begin{array}{c}\text { Total } \\
\mathbf{n}=\mathbf{2 8 2 0 , ( \% )}\end{array}$ \\
\hline \multirow{2}{*}{ RDT } & Positive & $79(8.3)$ & $56(5.6)$ & $56(6.4)$ & $191(6.8)$ \\
& Negative & $869(91.7)$ & $936(94.4)$ & $824(93.6)$ & $2629(93.2)$ \\
\hline \multirow{2}{*}{ Microscopy } & Positive & $33(3.5)$ & $81(8.2)$ & $74(8.4)$ & $188(6.7)$ \\
& Negative & $915(96.5)$ & $911(91.8)$ & $806(91.6)$ & $2632(93.3)$ \\
\hline
\end{tabular}

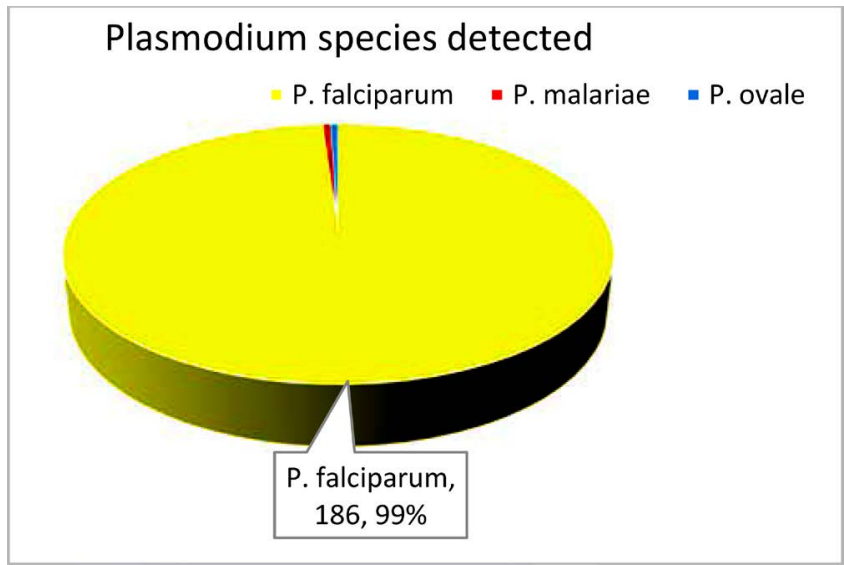

Figure 2. Distribution of Plasmodium species detected.

Table 3. Distribution of Species detected in the different States.

\begin{tabular}{ccccc}
\hline Specie & Akwa Ibom & Delta & Rivers & Fischer's Exact \\
\hline P. falciparum & $32(96.9)$ & $81(100.0)$ & $73(98.7)$ & \\
P. malariae & $1(3.1)$ & $0(0.0)$ & $0(0.0)$ & 6.26 \\
P. ovale & $0(0.0)$ & $0(0.0)$ & $1(1.35)$ & $(\mathrm{p}=0.1 .80)$ \\
Total & $33(100.0)$ & $\mathbf{8 1 ( 1 0 0 . 0 )}$ & $\mathbf{7 4 ( 1 0 0 . 0 )}$ & \\
\hline
\end{tabular}


Table 4. Comparison of diagnostic accuracy of mRDT compared to Microscopy.

\begin{tabular}{|c|c|c|c|}
\hline \multirow{2}{*}{ Test (RDT) } & \multicolumn{2}{|c|}{ Disease (Microscopy) } & \multirow{2}{*}{ Total } \\
\hline & Yes & No & \\
\hline Yes & $188(\mathrm{a})$ & 3 (b) & $191(a+b)$ \\
\hline No & $0(\mathrm{c})$ & $2629(\mathrm{~d})$ & $2629(c+d)$ \\
\hline Total & $188(a+c)$ & $2632(b+d)$ & $2820(a+b+c+d)$ \\
\hline \multicolumn{2}{|c|}{ Sensitivity } & $\mathrm{a} /(\mathrm{a}+\mathrm{c})$ & $100.0 \%$ \\
\hline \multicolumn{2}{|c|}{ Specificity } & $d /(b+d)$ & $99.9 \%$ \\
\hline \multicolumn{2}{|c|}{ Positive predictive value } & $a /(a+b)$ & $94.8 \%$ \\
\hline \multicolumn{2}{|c|}{ Negative predictive value } & $d /(c+d)$ & $100.0 \%$ \\
\hline \multicolumn{2}{|c|}{ Prevalence of the disease } & $(a+b) /(a+b+c+d)$ & $6.8 \%$ \\
\hline \multicolumn{2}{|c|}{ Accuracy $^{\star}$ (extent of correct classification) } & $(a+d) /(a+b+c+d)$ & $99.9 \%$ \\
\hline
\end{tabular}

parasitaemia while Table 3 shows the species distribution according to states.

\subsection{Diagnostic Accuracy}

An analysis of the diagnostic accuracy of the RDT test compared to microscopy showed that RDT used in this survey has high diagnostic accuracy (99\%) compared to microscopy Table 4.

\section{Discussion}

The Demographics show that many women in the Niger Delta region get married at earlier ages though well educated. This is important because enlightenment and education of individuals are proven means of primary prevention of infectious diseases including malaria [12].

The prevalence of Plasmodium parasitaemia observed in the pregnant women we studied is much lower than that of other studies done previously in Rivers State and other states in the Niger Delta region of Nigeria. Which reported much higher prevalence in years past [12] [13] [14] [15]. This is very exciting as it reveals a downward trend in prevalence, an indication of the success of the malaria prevention strategies implemented among pregnant women; including intermittent preventive treatment of malaria in pregnancy (IPTp) administered during antenatal care and use of insecticide-treated bed nets as recommended by WHO and the Nigeria Malaria Elimination Program. Despite the increased prevalence observed between 2016 and 2017 in the WHO African Region, case incidence levels were reported to have declined from 294 in 2010 to 229 in 2018, representing a $22 \%$ reduction [7]. The implication is that we have obviously made remarkable progress towards the WHO Global technical strategy for malaria 2016-2030 that among other targets aims to reduce malaria case incidence by at least $90 \%$ by the year 2030. Pregnant women are an important group to focus on in this regard.

Plasmodium falciparum is the most prevalent malaria parasite in the WHO 
African Region, having accounted for $99.7 \%$ of estimated malaria cases in 2018 . Our study also reflects the same, with $P$. falciparum accounting for $99 \%$ of all infections in our study cohort [7].

The ease of use of RDTs and high diagnostic accuracy in comparison with Light microscopy has made their development a major contributor to malaria control globally. RDTs unlike microscopic diagnosis are quite easy to perform, do not require complex equipment, electricity supply and highly skilled personnel while providing rapid and reliable results as has been reported severally [16] [17].

Our findings also agree with reports of their comparability when used in diagnosis of acute malaria with only $0.1 \%$ difference in detection observed between both methods; RDT being higher. This difference could possibly be due to false positive result with the RDT since RDTs have been known to remain positive for a time frame of about $10-14$ days following successful treatment of malaria. Dalrymple et al. showed that half of RDTs that detect the antigen histidine-rich protein II (HRP2) as was done in our study, are still positive 15 days post-treatment, with about $5 \%$ remaining positive 36 days following anti-malarial treatment [18]. An important limitation of RDTs includes not being able to detect some infections with lower parasite density as their sensitivity reduces with reducing parasite density [19] [20] [11]. Microscopy is able to overcome this as well as detect less common species such as $P$. ovale and $P$. malariae which RDTs may not, as seen in our study.

These findings imply that malaria prevalence in the Niger Delta is on the decline and the goal for of malaria elimination is in sight. However concerted efforts in prevention and prompt diagnosis and treatment are imperative to push the elimination efforts to its destination. In addition, RDTs were shown to be quite useful for case detection implying that its use is quite advantageous in resource limited settings and should be implemented as point of care testing at every health care service delivery setting in the country.

The strengths of this study are that it employed a large sample size across three states representing the Niger Delta region of Nigeria, and that it used both $\mathrm{RDT}$ and microscopy to diagnose malaria cases. The limitation of the study is its cross-sectional design and as such treatment and pregnancy outcomes were beyond the scope of the study. However cross section studies have been showed to be adequate for prevalence studies.

\section{Conclusion}

The prevalence of Plasmodium parasitaemia among pregnant women in the Niger Delta region of Nigeria has reduced considerably. This gives credence to the malaria preventive strategies applied in pregnancy. We therefore encourage the promotion of these measures as they have shown effectiveness. When properly stored and used as recommended, RDTs compare favorably with microscopy in diagnosis of malaria; therefore, no case of malaria should go undiagnosed 
due to a facility's incapability to carry out microscopic diagnosis.

\section{Acknowledgements}

The study is part of a composite study coordinated by the Niger Delta Development Company (NDDC) Professorial Chair on Malaria Elimination and Phytomedicine Research, Centre for Malaria Research and Phytomedicine, University of Port Harcourt, Rivers State, Nigeria.

\section{Authors' Contributions}

This work was carried out in collaboration among all authors. Author CAN wrote the protocol. Authors IMS, CIA, ARN, FON, OKO and CAN managed the research design, processes and co-ordination. Author OIL wrote the drafts of the manuscript and managed the literature searches. Author OM performed the statistical analysis. All authors read and approved the drafts and final manuscript.

\section{Conflicts of Interest}

The authors declare no conflicts of interest regarding the publication of this paper.

\section{References}

[1] Sutherland, C.J., Tanomsing, N., Nolder, D., Oguike, M., Jennison, C., Pukrittayakamee, S., Dolecek, C., Hien, T.T., Do Rosario, V.E., Arez, A.P., Pinto, J., Michon, P., Escalante, A.A., Nosten, F., Burke, M., Lee, R., Blaze, M., Otto, T.D., Barnwell, J.W., Pain, A., Williams, J., White, N.J., Day, N.P., Snounou, G., Lockhart, P.J., Chiodini, P.L., Imwong, M. and Polley, S.D. (2010) Two Nonrecombining Sympatric Forms of the Human Malaria Parasite Plasmodium ovale Occur Globally. The Journal of Infectious Diseases, 201, 1544-1550. https://doi.org/10.1086/652240

[2] Oguike, M.C., Betson, M., Burke, M., Nolder, D., Stothard, J.R., Kleinschmidt, I., Proetti, C., Bousema, T., Ndounga, M., Tanabe, K., Ntege, E., Culleton, R. and Sutherland, C.J. (2011) Plasmodium ovale Curtisi and Plasmodium ovale Wallikeri Circulate Simultaneously in African Communities. International Journal for Parasitology, 41, 677-683. https://doi.org/10.1016/j.ijpara.2011.01.004

[3] Kasso, T., Oboro, I.L., Maduka, O., Awopeju, A.T.O., Paul, N.I., Yaguo-Ide, L.E., Chijioke-Nwauche, I.N., Ogoro, M., Otto, G. and Nwauche, C.A. (2019) Malaria Preventive Practices among Pregnant Women in Akwa Ibom State, Southern Nigeria. Archives of Current Research International, 19, 1-8. https://doi.org/10.9734/acri/2019/v19i330158

[4] Sitali, L., Chipeta, J., Miller, J.M., Moonga, H.B., Kumar, N., Moss, W.J. and Michelo, C. (2015) Patterns of Mixed Plasmodium Species Infections among Children Six Years and under in Selected Malaria Hyper-Endemic Communities of Zambia: Population-Based Survey Observations. BMC Infectious Diseases, 15, 204. https://doi.org/10.1186/s12879-015-0935-7

[5] National Malaria Elimination Program (Nigeria), and ICF International (2016) 2015 Nigeria Malaria Indicator Survey: Atlas of Key Indicators. National Malaria Elimination Program (Nigeria), and ICF International, Rockville. https://dhsprogram.com/pubs/pdf/ATR17/ATR17.pdf 
[6] Association for Reproductive and Family Health. World Malaria Day 2018: How Nigeria Can Beat Malaria for Good.

https://arfh-ng.org/world-malaria-day-2018-how-nigeria-can-beat-malaria-for-goo d

[7] WHO, World Malaria Report 2019. https://www.who.int/publications/i/item/9789241565721

[8] Federal Ministry of Health (2015) Malaria Indicator Survey (MIS). Abuja.

[9] Jukes, M.C., Pinder, M., Grigorenko, E.L., Smith, H.B., Walraven, G., Bariau, E.M., et al. (2006) Long-Term Impact of Malaria Chemoprophylaxis on Cognitive Abilities and Educational Attainment: Follow-Up of a Controlled Trial. PLOS Clinical Trials, 1, e19. https://doi.org/10.1371/journal.pctr.0010019

[10] Clarke, S.E., Jukes, M.C., Njagi, J.K., Khasakhala, L., Cundill, B., Otido, J., et al. (2008) Effect of Intermittent Preventive Treatment of Malaria on Health and Education in Schoolchildren: A Cluster-Randomised, Double-Blind, Placebo-Controlled Trial. The Lancet, 372, 127-138. https://doi.org/10.1016/S0140-6736(08)61034-X

[11] Cunningham, J., Jones, S., Gatton, M.L., Barnwell, J.W., Cheng, Q., Chiodini, P.L., et al. (2019) A Review of the WHO Malaria Rapid Diagnostic Test Product Testing Programme (2008-2018): Performance, Procurement and Policy. Malaria Journal, 18, 387. https://doi.org/10.1186/s12936-019-3028-z

[12] American Academy of Family Physicians (2015) Learning Matters: How Education Affects Health.

https://www.aafp.org/news/blogs/leadervoices/entry/learning matters how educati on affects.html

[13] Wogu, M. (2014) Prevalence of Malaria Parasite Infection among Pregnant Women Attending Antenatal Clinics in Port Harcourt, Rivers State, Nigeria. International Journal of Tropical Disease and Health, 3, 126-132. https://doi.org/10.9734/IJTDH/2013/2738

[14] Inah, S.A., Ejemot-Nwadiaro, R., Inah, J.A. and Eko, J.E. (2017) Prevalence of Malaria among Pregnant Women and Children under Five Years in Abi Local Government Area, Cross River State, Nigeria. Asian Journal of Medicine and Health, 7, 1-7. https://doi.org/10.9734/AJMAH/2017/35911

[15] Nnah, E.W. and Kasso, T. (2017) The Prevalence of Malaria and Helminth Infection in Pregnancy at Booking and Their Relationship to Anaemia at the University of Port Harcourt Teaching Hospital. International Journal of Tropical Disease and Hygiene, 28, 1-9.

[16] Azikiwe, C.C.A., Ifezulike, C.C., Siminialayi, I.M., Amazu, L.U., Enye, J.C. and Nwakwunite, O.E. (2012) A Comparative Laboratory Diagnosis of Malaria: Microscopy versus Rapid Diagnostic Test Kits. Asian Pacific Journal of Tropical Biomedicine, 2, 307-310. https://doi.org/10.1016/S2221-1691(12)60029-X

[17] Metoh, T.N., Fru, C.T., FonGah, P. and Zhoul, X. (2020) A Comparative Assessment of Rapid Diagnosis Test (RDT) versus Microscopy for Malaria Diagnosis in Health Care Facilities. Version 1. https://doi.org/10.21203/rs.2.20202/v1

[18] Dalrymple, U., Arambepola, R., Gething, P.W. and Cameron, E. (2018) How Long Do Rapid Diagnostic Tests Remain Positive after Anti-Malarial Treatment? Malaria Journal, 17, 228. https://doi.org/10.1186/s12936-018-2371-9

[19] Rapid Diagnostic Tests: How They Work. CDC. https://www.cdc.gov/malaria/malaria worldwide/reduction/dx rdt.html

[20] Wongsrichanalai, C., Barcus, M.J., Muth, S., Sutamihardja, A. and Wernsdorfer, 
W.H. (2007) A Review of Malaria Diagnostic Tools: Microscopy and Rapid Diagnostic Test (RDT). In: Breman, J.G., Alilio, M.S. and White, N.J., Eds., Defining and Defeating the Intolerable Burden of Malaria III: Progress and Perspectives: Supplement to Volume 77(6) of American Journal of Tropical Medicine and Hygiene, American Society of Tropical Medicine and Hygiene, Northbrook, 119-127. https://www.ncbi.nlm.nih.gov/books/NBK1695 